\title{
Non-muscle invasive bladder cancer (NMIBC): boiling arena and promissory future
}

\author{
Leonardo O. Reis ${ }^{1,2}$ (D \\ Published online: 1 August 2019 \\ ○) Springer-Verlag GmbH Germany, part of Springer Nature 2019
}

Non-muscle invasive bladder cancer (NMIBC) is a rapidly developing and intriguing field with many challenging faces while cystoscopy, transurethral resection, and intravesical bacillus Calmette-Guérin (BCG) have withstood the test of time remaining the gold standards; there has been an explosion of research in this scenario.

This NMIBC Topic Issue of the World Journal of Urology (WJU) puts together pearls covering from screening and diagnosis (potential biomarkers) to treatment (from established to new and developing therapies) and surveillance (further understanding the gold standard cystoscopy and complementary cytology), on original articles, metaanalysis, and comprehensive reviews signed by many of the brightest star authors in the bladder cancer landscape to whom we extend our feelings of appreciation and gratitude.

García-Perdomo et al. describe an association between FGFR3 mutated gene and the diagnosis of bladder cancer, which has not occurred with the CDKN2A gene in a systematic review with meta-analysis and discuss the FGFR3 gene as a putative biomarker allowing future screening strategies [1].

In this regard, while current guideline recommendations across major societies do not strongly advocate for diagnostic biomarkers in NMIBC use due to moderate-level evidence, Faiena et al. bring an overview of potential biomarkers with increasing interest in DNA and RNA alterations in cancer. The validation of these findings will perhaps lead to highly refined and accurate markers affecting our management of NMIBC [2].

Peyton et al. update the treatment of intravesical therapies for NMIBC, from peri-operative intravesical chemotherapy

Leonardo O. Reis

reisleo.1@gmail.com

1 Department of Urology, University of Campinas, Campinas, SP, Brazil

2 Department of Urology, Pontifical Catholic University of Campinas, Campinas, SP, Brazil for low-risk patients to a well-performed transurethral resection of bladder tumor (TURBT) and immunotherapy as the preferred intravesical therapy for high-risk patients and risk stratification of intermediate-risk patients with personalized recommendations. The details and timing of recurrence are critical with strong prognostic value and combination therapies and clinical trials are important in well-selected patients [3].

Werntz et al. highlight the many clinical trials underway examining different therapeutic approaches in an effort to provide safe and effective bladder sparing options considering the current poor intravesical options for second-line treatment and radical cystectomy remaining as the gold standard in the management of high-risk NMIBC [4].

Duplisea et al. explore, from bench to bedside, the development of interferon-based gene therapy in a team with 15 years of experience developing IFN-based gene therapy to treat BCG unresponsive bladder cancer [5].

Gupta et al. explore the accuracy of urine cytology after NMIBC intravesical therapy (IT) and conclude that the cytology interpretation is not necessarily a false positive secondary to an inflammatory state following IT once it maintains a high specificity for high-grade tumors compared to established rates in the literature and can be used to identify patients at risk for disease recurrence and progression. This adds to the puzzling patient pre-test probabilities, variations in cytology interpretation, and differences in collection methods [6].

Mossanen et al. evaluate the cost of surveillance for NMIBC based on risk categories, identifying the primary driver of costs as the progression to muscle-invasive disease rather than frequent surveillance cystoscopy [7].

Datovo et al. in a prospectively maintained database highlight the impact of the non-adherence to follow-up cystoscopy in high-risk NMIBC, which can be as high as $18 \%$ and might be associated with more than twice progression risk increment ( $2.33 \mathrm{HR}, p=0.014,95 \%$ CI $1.18-4.59$ ) impacting the disease natural history and its prognosis [8]. 
The clinical interpretation of these results on the surveillance cystoscopy encourage patients to attend follow-up visits and further emphasize the need for efforts to detect intermediate- or high-risk disease before it progresses with potential improvement on clinical and economic outcomes, important determinants of overall sustainability by limiting healthcare costs to improve quality of care for patients with bladder cancer [7, 8].

Moreover, the current Topic Issue papers highlight the upshots of many pressures, from the standard of care limitations to BCG shortage, making the field a boiling arena with a promissory future and many improvement channels and opportunities ranging from screening, diagnosing, and surveillance to better understanding of mechanisms and strains [9], improving and maybe replacing BCG.

Funding The "National Council for Scientific and Technological Development" funds Dr. Reis-CNPq, Research productivity: 304747/2018-1.

\section{Compliance with ethical standards}

Conflict of interest The author declares that they have no conflict of interest.

\section{References}

1. García-Perdomo HA, Usubillaga-Velasquez JP, Zapata-Copete JA, Reis LO (2019) Mutations in CDKN2A and the FGFR3 genes on bladder cancer diagnosis: a systematic review and meta-analysis. World J Urol. https://doi.org/10.1007/s00345-019-02779-7
2. Faiena I, Rosser CJ, Chamie K, Furuya H (2018) Diagnostic biomarkers in non-muscle invasive bladder cancer. World J Urol. https://doi.org/10.1007/s00345-018-2567-1

3. Peyton CC, Chipollini J, Azizi M, Kamat AM, Gilbert SM, Spiess PE (2018) Updates on the use of intravesical therapies for nonmuscle invasive bladder cancer: how, when and what. World J Urol. https://doi.org/10.1007/s00345-018-2591-1

4. Werntz RP, Adamic B, Steinberg GD (2018) Emerging therapies in the management of high-risk non-muscle invasive bladder cancer (HRNMIBC). World J Urol. https://doi.org/10.1007/s0034 5-018-2592-0

5. Duplisea JJ, Mokkapati S, Plote D, Schluns KS, McConkey DJ, Yla-Herttuala S, Parker NR, Dinney CP (2018) The development of interferon-based gene therapy for BCG unresponsive bladder cancer: from bench to bedside. World J Urol. https://doi. org/10.1007/s00345-018-2553-7

6. Gupta M, Milbar N, Tema G, Pederzoli F, Chappidi M, Kates M, Vanden Bussche CJ, Bivalacqua TJ (2019) Impact of intravesical therapy for non-muscle invasive bladder cancer on the accuracy of urine cytology. World J Urol. https://doi.org/10.1007/s00345-01802624-3

7. Mossanen M, Wang Y, Szymaniak J, Tan WS, Huynh MJ, Preston MA, Trinh QD, Sonpavde G, Kibel AS, Chang SL (2018) Evaluating the cost of surveillance for non-muscle-invasive bladder cancer: an analysis based on risk categories. World J Urol. https ://doi.org/10.1007/s00345-018-2550-x

8. Datovo JCF, Neto WA, Mendonça GB, Andrade DL, Reis LO (2019) Prognostic impact of non-adherence to follow-up cystoscopy in non-muscle-invasive bladder cancer (NMIBC). World J Urol. https://doi.org/10.1007/s00345-019-02697-8

9. Carneiro BDB, Sanches BCF, Andrade DL, Voris BRI, Reis LO (2019) Moreau strain bacillus Calmette-Guérin low versus standard dose in the treatment of high-grade $\mathrm{T} 1$ bladder cancer: a retrospective observational cohort study. Clin Genitourin Cancer. 17(4):e779-e783. https://doi.org/10.1016/j.clgc.2019.04.003

Publisher's Note Springer Nature remains neutral with regard to jurisdictional claims in published maps and institutional affiliations. 